196601, г. Санкт-Петербург - Пушкин, Петербургское шоссе, 2.

Тел.: (812) 451-76-18.

ключевые слова: энергия возбуждения; собс- твенная энергия атома; дискретное изменение заряда ядра; память оптического спектра атома; составные конструкиии решеток в молекулярном азоте.

\title{
ANALYSIS OF MOLECULAR BONDS BY THE SPECTRUM OF NITROGEN ATOMS IN ORDER TO OPTIMIZE THE SYNTHESIS OF MINERAL FERTILIZERS
}

Gusev Valery Pavlovich, Candidate of Technical Sciences, Engineer, Limited Liability Company "ALAN", Russia.

Shkrabak Vladimir Stepanovich, Doctor of Technical Sciences, Professor of the chair "Safety of Technological Processes and Productions", St. Petersburg State Agrarian University. Russia.

Orlov Pavel Sergeyevich, Doctor of Technical Sciences, Professor, Head of the chair "Electrification", Yaroslavl State Agricultural Academy. Russia.

Shkrabak Roman Vladimirovich, Candidate of Technical Sciences, Associate Professor, Head of the chair "Safety of Technological Processes and Productions", St. Petersburg State Agrarian University. Russia.

Keywords: excitation energy; self-energy of an atom; discrete change in the charge of the nucleus; memory of the optical spectrum of the atom; composite lattice designs in molecular nitrogen.
The model of the structure of the crystal cubic lattice proposed by the authors takes into account the presence of short and long diagonal bonds passing along the faces and through the center of the elementary cube. The mechanism of energy distribution between two and three valence electrons of the $N$ atom in the ground and excited states is described. It is shown that the optical spectrum of the $N$ atom is mirrored on the set of energies of the $2 p 2$ term, called the spectral memory of the nitrogen atom by the authors. The mechanism of "trigger of excitation" of $N$ atoms is described for the first time. The optical spectrum of $N$ atoms determines the energies of the FCC $\rightarrow$ HCP phase transitions; solid $\rightarrow$ liquid phase of the hcp; boiling and melting points. The error in calculating the temperatures of phase transitions is $\pm 3.3 \%$, and the density at the boiling and melting points is not more than $1 \%$.

\section{АВТОМАТИЗИРОВАННАЯ СИСТЕМА УПРАВЛЕНИЯ ТЕХНОЛОГИЧЕСКИМ ПРОЦЕССОМ ЗЕРНООЧИСТИТЕЛЬНОЙ МАШИНЫ}

\author{
ЗАГОРУЙКО Михаил Геннадьевич, Федеральный научный агроинженерный центр ВИМ \\ СТАРОСТИН Иван Александрович, Федеральный научный агроинженерный центр ВИМ \\ КОЦАРЬ Юрий Алексеевич, Саратовский государственный аграрный университет \\ имени Н.И. Вавилова
}

В статъе рассмотрены основные проблемы, возникающие при работе серийно выпускающихся зерноочистительных машин «Петкус-Гигант» К531. Для решения обозначенных проблем предложены комплект съемного оборудования, позволяющий с минимальными финансовъми затратами автоматизировать проиесс очистки зерна, и система управления, осуществляющая контроль за содержанием сорных примесей в очищенном зерне, товарного зерна в выходах легких примесей из каналов первой и второй аспирации, въходе мелких примесей (проход нижнего решета) и выходе крупных примесей (сход с верхнего решета). Предлагаемый комплект включает в себя датчик уровня, камеры, процессор с блоком управления, исполнительные устройства в виде сервоприводов. Описан алгоритм работы системы управления технологическим процессом зерноочитительной машины. Постоянный контроль и корректировка параметров протекания технологического процесса системой управления позволяют удовлетворить все предъявляемые требования.

Введение. Одной из самых важных операций послеуборочной обработки зерна является очистка, от качества которой зависит насколько долго зерно сможет храниться без каких-либо проблем и потерь, а также качество продуктов его переработки.

На сельскохозяйственных предприятиях используется зерноочистительное оборудование различного типа, отличающееся конструкцией, производительностью, эффективностью очистки и т.д. Перечень существующего оборудования очень велик [2]. Выбор оборудования осуществляется в зависимости от финансового состояния предприятия и поставленных задач [5].
Как показывает практика, наиболее востребованными у отечественных сельхозтоваропроизводителей являются зерноочистительные машины «Петкус» фирмы Petkus Whuta (Германия). Эти машины были разработаны в тесном сотрудничестве с Россией, опробованы в различных условиях и повсеместно признаны оптимальными и ценными для сельского хозяйства страны. Популярность их обусловлена высоким качеством очистки зерна при сравнительно низкой цене машин. В большинстве случаев это восстановленные машины, которые продолжают активно использоваться на сельскохозяйственных предприятиях. Наиболее универсальной и ши- 
роко применяемой машиной в России является «Петкус-Гигант» К531.

Зерноочистительная машина «Петкус-Гигант» К531 применяется для очистки зерновых, бобовых, масличных и других культур, предназначенных для продажи на потребительские предприятия, а также для подготовки семенного материала. Машина может использоваться как очистительное и сортировальное оборудование в поточной линии для обработки зерна.

Методика исследований. Для решения основных проблем, возникающих при работе серийно выпускающихся зерноочистительных машин «Петкус-Гигант» К531, предложены комплект съемного оборудования, позволяющий с минимальными финансовыми затратами автоматизировать процесс очистки зерна, и система управления, осуществляющая контроль за содержанием сорных примесей в очищенном зерне, товарного зерна в выходах легких примесей из каналов первой и второй аспирации, выходе мелких примесей (проход нижнего решета) и выходе крупных примесей (сход с верхнего решета).

Результаты исследований. Принцип работы зерноочистительной машины «Петкус-Гигант» К531 основан на совместном действии аспирации воздушных потоков и амплитудных движений решетных станов (рис. 1). В загрузочный бункер подается зерно, которое необходимо очистить. Посредством подающего валика зерно попадает на первый канал аспирации, где одновременно с легковесной засоренностью, имеющей большую парусность, удаляются легкие пылевидные частицы. Далее очищаемая масса переходит на верхнее решето, где происходит удаление грубых и крупных примесей. Очистка верхнего решета осуществляется молотками-подбивальщиками. Особенностью верхнего решета является крупность отверстий (ячеек), подобранных из условий вида и размера зерна, вследствие чего основная масса просыпается через него на нижнее решето. На нижнем решете происходит просеивание более мелких примесей из материала. Нижние решета очищаются щетками, которые выполняют счесывание по тыльной стороне решета. Очищенное зерно попадает во второй канал аспирации, где дополнительно отделяются легкие и средние по массе примеси, а также некачественное зерно. Переработанное зерно направляется через боковой канал загрузки на упаковку в мешки или прямо через каналы на триерные блоки в зависимости от вида зерна и задач по переработке. С помощью триерного блока отделяются примеси по геометрическому принципу и отличию зерна качественного от некачественного и сорняков. В зависимости от вида зерна имеются триерные цилиндры с различными видами ячеек. После этого готовое зерно направляется на упаковку в мешки.

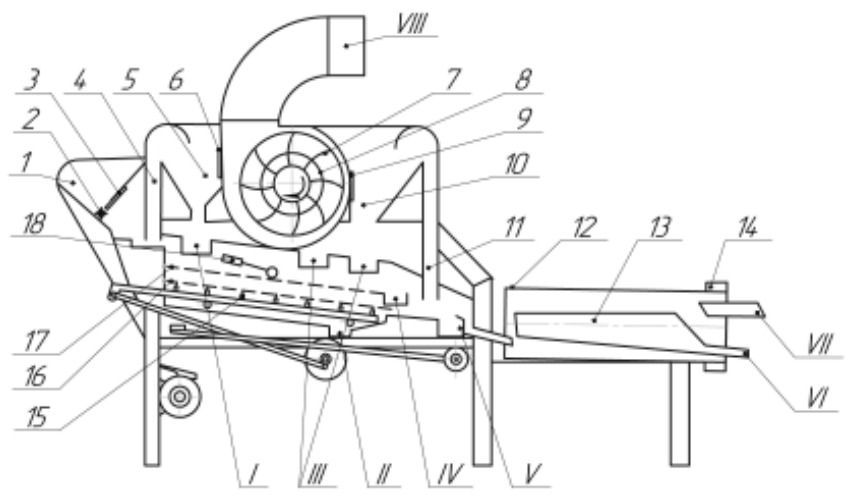

Рис. 1. Устройство зерноочистительной машины «Петкус-Гигант» К531: 1 - приемный бункер;

2 - питающий валик с регулировочной заслонокой; 3 - регулировочная заслонка; 4 - канал первой аспиращии; 5 - отстойная камера; 6 - заслонка управления потоком воздуха первой аспирации;

7 - вентилятор; 8 - сетчатый иилиндр (мякиноотделитель); 9 - заслонка управления потоком воздуха второй аспирации; 10 - отстойная камера; 11 - канал второй аспирации; 12 - триеры;

13 - лоток триера; 14 - лопастное колесо; 15 - щетки; 16 - нижнее решето;

17 - верхнее решето; 18 - молоток-подбивальщик; I - выход легких примесей (из канала первой аспирации);

II - въход мелких примесей (проход нижнего решета); III - выход легких примесей (из канала второй аспирации);

IV - въход крупных примесей (сход с верхнего решета);

V - выход очищенного материала (при работе с выключенными триерами);

VI - выход коротких примесей;

VII - выход очищенного материала (при работе с включенными триерами); VIII - выход пыли

В целом машина имеет высокий уровень производительности, надежности и энергосбережения. Но работа данного оборудования предполагает постоянный контроль со стороны оператора за объемом подаваемой зерновой массы и качеством очистки зерна $[3,6]$. Имеется ряд проблемных вопросов, решение которых в процессе работы машины желательно без участия человека. Так, при отсутствии схождения зерновой массы из загрузочного бункера или значительном снижении потока материала через подающий валик оставшееся зерно на лотке первого аспирационного канала зачастую забирается усилившимся потоком воздуха и попадает в зерно-отходы [2]. Кроме того, регулирующая заслонка, находящаяся на загрузочном бункере, в условиях постоянных вибраций может некорректно работать и произвольно изменять подачу зерновой массы, что влечет за собой увеличение слоя на решетном стане, который в свою очередь может не только не очищать должным образом зерновой поток, но и забиваться. При несоответствии слоя зерна, поступающего во второй канал аспирации, оптимальному также будет иметь место отклонение в качестве очистки: излишняя масса зерна не будет должным образом продуваться, что повлечет за собой сход некачест- 
венной продукции в готовую, или же будет происходить всасывание потоками воздуха качественного зерна, которое будет направлено в отходы.

Приведенные выше проблемы в процессе зерноочистки на практике приходится решать за счет постоянного контроля со стороны оператора. Он должен следить за подачей материала в машину, работоспособностью всех узлов, показателями качества протекающего процесса [3].

Проведенные исследования показывают, что некорректная работа зерноочистительной машины приводит к потерям от 5 до $15 \%$ чистого зерна, попадающего в отходы либо к снижению качества получаемого очищенного зерна, вследствие чего может потребоваться дополнительная очистка. Особенно это важно в семеноводстве, когда стоимость получаемых семян весьма высока и потери должны быть минимальными.

В современных реалиях работы на сельскохозяйственных предприятиях предлагается решение данной проблемы за счет комплексной автоматизации процесса очистки на зерноочистительных машинах [4].

Выпускающееся в настоящее время автоматизированное оборудование для сортировки зерна и семян весьма сложно и дорого [3]. С целью устранения вышеуказанных недостатков предлагается разработать комплект съемного оборудования, позволяющий с минимальными финансовыми затратами автоматизировать процесс очистки зерна и семян на агрегатах типа «Петкус-Гигант» (рис. 2).

Предлагаемый комплект включает в себя датчик уровня, камеры, процессор с блоком управления, исполнительные устройства в виде сервоприводов. Применение цифровых систем управления технологическим процессом позволяет значительно повысить производительность оборудования и качество получаемой продукции, снизить затраты труда и минимизировать влияние человеческого фактора на технологический процесс [7-9].

Для решения проблемы выдувания кондиционного зерна в моменты пуска или остановки, а также если в загрузочном бункере уровень подаваемого зерна снижается ниже оптимального, предлагается установить сервоприводы на заслонки вентилятора, частотный преобразователь на электродвигатель привода вентилятора, которые будут управляться сигналами от процессора. Это позволит осуществлять плавный пуск вентилятора и создавать необходимый поток воздуха в первой и второй камерах аспирации.

С целью контроля уровня материала в приемном бункере установлен датчик уровня 1 , который передает информацию в систему управления (процессор). При снижении уровня материала в приемном бункере ниже оптимального значения датчик уровня 1 передает сигнал в систему управления, которая увеличивает объем подаваемого в

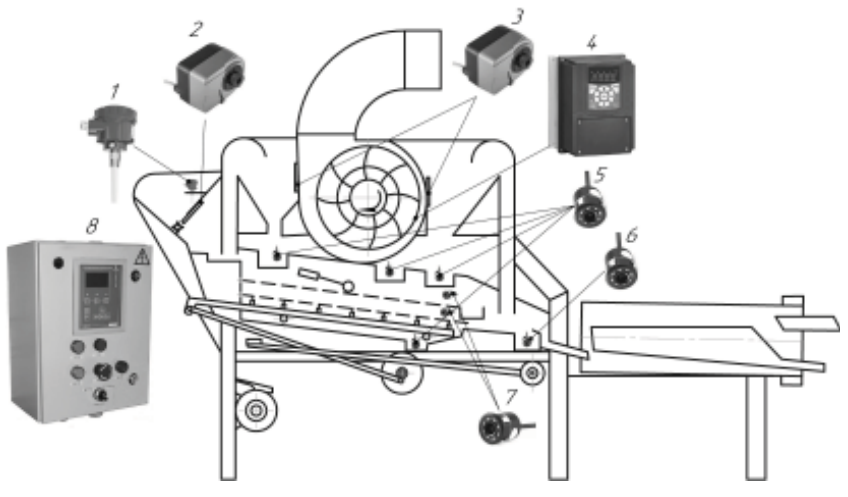

Рис. 2. Дооснащение зерноочистительной машины «Петкус-Гигант» К531:1 - датиик уровня;

2 - сервопривод регулировочной заслонки; 3 - сервоприводы заслонок управления потоком воздуха первой и второй аспирации;

4 -частотный преобразователь двигателя привода вентилятора; 5 - камеры контроля отходов из каналов первой и второй аспирации;

6 - камера контроля очищенного материала;

7 - камеры контроля работы верхнего и нижнего решет; 8 - щит управления с процессором

приемный бункер материала за счет увеличения производительности устройства загрузки бункера (питающей нории, транспортера и т.п.) (на рисунке не показано).

Регулировка объема подачи зерновой массы в машину осуществляется сервоприводом 2 , который управляет регулировочной заслонкой.

Регулировка потоков в первой и второй камерах аспирации осуществляется сервоприводами 3 заслонок и частотным преобразователем 4 электродвигателя привода вентилятора.

Для контроля наличия в легких отходах первой и второй аспирации товарного зерна установлены камеры 5, которые в режиме «онлайн» фиксируют сходящие с лотка отходы и передают эти данные для обработки в управляющую систему.

Качество очистки зерна контролируется установленной на выходе очищенного зерна камерой 6. Применение технологии машинного зрения позволяет в режиме реального времени осуществлять корректировку параметров протекания технологического процесса очистки зерна в зависимости от качества получаемого продукта, запрограммировав систему на определенные параметры получаемого продукта (\% засоренности, дробление зерна, потери в отходах).

Для контроля состояния решет применяются также технологии машинного зрения. Над верхним и нижним решетами установлены камеры, которые в режиме «онлайн» фиксируют поверхности решет, передают информацию в процессор, где происходит ее обработка, оценивается уровень загрузки и выявляются места, в которых произошло забивание решет.

Критериями оптимизации процесса являются содержание сорных примесей в очищенном зерне $X_{\text {к.с }}$, содержание фракций товарного зерна в выходах легких примесей из каналов первой и второй аспирации $X_{\text {т.з.с.1 }}$ и $X_{\text {т.з.с.2. }}$, выходе мелких примесей 
(проход нижнего решета) $X_{\text {т.з.с.з }}$, выходе крупных примесей (сход с верхнего решета) $X_{\text {т.з.с.4 }}$.

Работа системы управления в процессе очистки зерна будет направлена на получение максимально очищенного зерна $X_{\text {к.с }}$ при минимальных потерях товарного зерна в отходах $X_{\text {т.з.с.1 }}, X_{\text {т.з.с.2 }}$, $X_{\text {т.з.с.з }}, X_{\text {т.з.с.4 }}$ и максимальной подачи $Q$.

В системе уравнений данные условия примут вид:

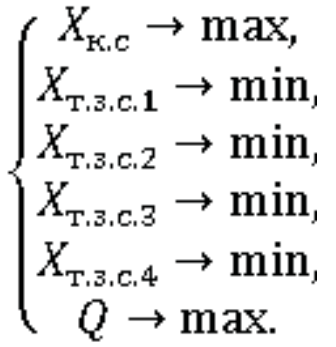

Содержание сорных примесей в чистом зерне $X_{\text {к.с }}$ зависит от работы всей системы очистки, в частности от корректной работы верхнего и нижнего решет, воздушных потоков первой и второй аспираций, которые обусловлены степенью открытия заслонок управления потоком первой и второй аспирации $\boldsymbol{\beta}_{1}$ и $\boldsymbol{\beta}_{2}$, частотой вращения вентилятора $n$, степенью открытия регулировочной заслонки подачи материала $\alpha$.

Содержание фракций товарного зерна в выходах легких примесей из каналов первой и второй аспирации $X_{\text {т.з.с.1 }}, X_{\text {т.з.с. } 2}$ зависят от степени открытия заслонок управления потоком первой и второй аспирации $\boldsymbol{\beta}_{1}$ и $\boldsymbol{\beta}_{2}$, частоты вращения вентилятора $n$, степени открытия регулировочной заслонки подачи материала $\boldsymbol{\alpha}$.

Содержание фракций товарного зерна в выходах мелких примесей (проход нижнего решета) $X_{\text {т.з..3 }}$ и крупных примесей (сход с верхнего решета) $X_{\text {т.з.с.4 }}$ зависит от корректной работы верхнего и нижнего решет, отсутствия забивания решет.

Предложенная система уравнений лежит в основе системы управления технологическим процессом очистки материала на зерноочистительной машине, которая будет работать по следующему алгоритму (рис. 3) [1].

Предполагается, что изначально оператор самостоятельно подбирает и устанавливает верхнее и нижнее решета необходимого калибра в зависимости от культуры. Для запуска системы нажимают кнопку «Пуск», после чего вводят тип обрабатываемой культуры. В соответствии с обрабатываемой культурой система в процессе запуска машины устанавливает параметры технологического процесса, внесенные в систему управления: степень открытия регулирующей заслонки подачи, открытия заслонок первой и второй аспирации, которые регулируются системой контроля «онлайн» во время технологического процесса.

Нажимают кнопку «Старт» и система автоматически запускает вентилятор, задает ему определен- ную частоту вращения, регулирует степень открытия заслонок первой и второй аспирации, запускает привод верхнего и нижнего решет, открывает регулирующую заслонку подачи. В этот момент система и сама машина работают по предустановленным настройкам для данной культуры. Дальнейшее управление технологическим процессом осуществляется системой контроля техпроцесса.

Система контроля техпроцессом с помощью машинного зрения определяет качество очистки зерна, потери товарного зерна и регулирует параметры протекания процесса очистки для достижения максимальной очистки зерна и максимальной производительности при минимальных потерях товарного зерна в отходах. Система одновременно контролирует несколько параметров.

Система контроля техпроцесса оценивает допустимое содержание сорных примесей в зерне и в случае превышения допустимых значений увеличивает степень открытия заслонок первой и второй аспирации. Если это не позволяет достичь оптимальных параметров, то система снижает подачу материала.

Следующим контролируемым параметром является содержание товарного зерна на выходе легких примесей из каналов первой и второй аспирации. В случае превышения допустимых значений первым шагом является снижение степени открытия заслонок первой или второй аспирации. Если это не позволяет достичь оптимального значения контролируемых параметров, то система увеличивает подачу материала.

Система также контролирует допустимое содержание товарного зерна в выходе мелких примесей (проход нижнего решета) и выходе крупных примесей (проход верхнего решета). В случае превышения допустимых значений система сначала снижает подачу материала, если это не позволяет достичь оптимальных значений, система выдает предупреждение о необходимости провести контроль решет на соответствие параметрам обрабатываемых культур и останавливает техпроцесс. Оператору необходимо повторно проверить соответствие установленных решет обрабатываемой культуре.

Установленные над верхним и нижним решетами камеры контролируют работу решет и в случае, если они забиваются выдают предупреждение и останавливают техпроцесс. Устранение забивания производится оператором вручную после остановки машины.

В случае остановки технологического процесса системой или оператором последовательно активируется кнопка «Стоп», закрывается заслонка подачи материала, с определенной задержкой для очистки находящегося в машине материала останавливается механизм привода решет, закрываются заслонки первой и второй 


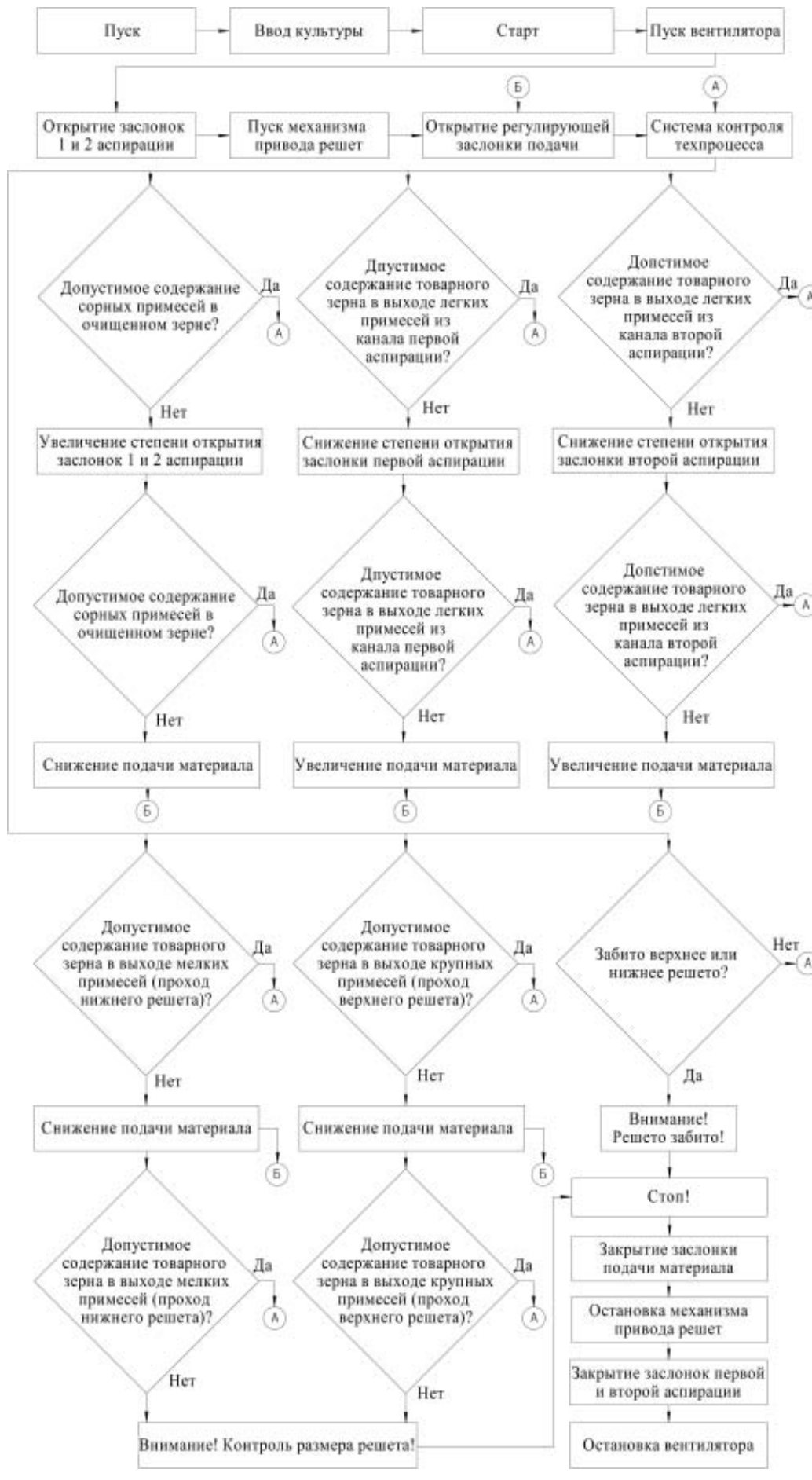

Рис. 3. Алгоритм работы системы управления технологическим процессом зерноочистительной машины «Петкус-Гигант» К531

аспирации, останавливается вентилятор.

Постоянный контроль и корректировка параметров протекания технологического процесса системой управления позволяют удовлетворить все предъявляемые к оборудованию требования по качеству очистки зерна и потерям товарного зерна.

Заключение. Применение предложенного решения экономически выгодно как для масштабных производств, так и для малых сельскохозяйственных предприятий, даже в случае ограниченных серий или штучного производства. Простые в использовании программные инструменты и съемное навесное оборудование помогают легко управлять и быстро перенастраивать оборудование при изменении параметров и условий работы. Автоматизация будет способствовать увеличению производительности, сокращению ручного и неэффективного труда, а также позволит снизить риск возникновения непредвиденных ситуаций.

\section{СПИСОК ЛИТЕРАТУРЫ}

1. Алгоритм моделирования технологий и составления технологических комплексов машин / М.Г. Загоруйко [и др.] // Материалы Междунар. науч.-практ. конф., посвящ. 80-летию со дня рождения профессора Кобы В.Г. - Саратов:, 2011. - С. 215-216.

2. Бурков А.И. Тенденции развития воздушно-решётных зерноочистительных машин на современном этапе // Вестник Казанского ГАУ. - 2015. - № 3 (37). - С. 67-71.

3. Жолобов Н.В., Маишев К.В. Устройство контроля и управления технологическим процессом пневмосепаратора зерна // Пермский аграрный вестник. - 2017. №3 (19). - С. 32-39.

4. Лобачевский Я.П., Дорохов А.С. Перспективные научно-технические проекты в сфере механизации и роботизации сельского хозяйства / Формирование единого научно-технологического пространства Союзного государства: проблемы, перспективы, инновации: сб. трудов конф. Минск, 2017. - С. 333-343.

5. Модель функционирования технологического процесса послеуборочной обработки зерна в отделении приема и предварительной очистки зернового вороха / Н.Н. Кузнецов[и др.] // Вестник Казанского ГАУ. 2018. № 4 (51). С. 114-118.

6. Разработка алгоритма работы системы автоматического поддержания подачи материала и расхода воздуха в пневмосепарационном канале зерноочистительной машины / М.С. Волхонов [и др.] // Вестник Кыргызского национального аграрного университета им. К.И. Скрябина. 2018. - № 2 (47). - С. 398-404.

7. Соловьев Д.А., Журавлева Л.А. Роботизированный оросительный комплекс «КАСКАД» // Аграрный научный журнал. - 2020. - № 1. - С. 74-78.

8. Средства автоматизации для управления Сельскохозяйственной техникой. / А.Ю. Измайлов [и др.] // Сельскохозяйственные машина и технологии. - 2017. № 3. - С. 3-9.

9. Управление производственными процессами полеводческих предприятий с использованием информационных и цифровых технологий / А.Ю. Измайлов [и др.] // Инновации в сельском хозяйстве. - 2019. № 1 (30). - C. 180-190.

Загоруйко Михаил Геннадьевич, канд. техн. наук, старший научный сотрудник, Федеральный научный агроинженерный центр ВИМ, Россия.

Старостин Иван Александрович, канд. техн. наук, старший научный сотрудник, Федеральный науч-

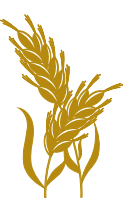


ный агроинженерный иеетр ВИМ, Россия.

109428, г. Москва, 1-й Институтский пр-д, 5.

Тел.: (915) 319-21-69.

Коцарь Юрий Алексеевич, $\partial$ - $р$ тех. наук, проф. кафедры «Техносферная безопасность и транспортно-технологические машины», Саратовский государственный аграрный университет имени Н.И. Вавилова. Россия.
410056, г. Саратов, ул. Советская, 60.

Тел.: (8452) 74-96-63.

Ключевые слова: зерно; зерноочистительная машина; автоматизация технологического процесса; система управления; алгоритм работы.

\title{
AUTOMATED PROCESS CONTROL SYSTEM FOR A GRAIN CLEANING MACHINE
}

Zagoruiko Mikhail Gennadyevich, Candidate of Technical Sciences, Senior Researcher, Federal Scientific Agroengineering Center VIM. Russia.

Starostin Ivan Aleksandrovich, Candidate of Technical Sciences, Senior Researcher, Federal Scientific Agroengineering Center VIM. Russia.

Kotsar Yuriy Alekseevich, Doctor of Technical Sciences, Professor of the chair "Technosphere Safety and Transport and Technological Machinery", Saratov State Agrarian University named after N.I. Vavilov. Russia.

Keywords: grain; grain cleaning machine; process automation; control system; algorithm of operation.

The article discusses the main problems that arise when working with commercially available grain cleaning ma- chines "Petkus-Giant" K531. To solve these problems, we offer a set of removable equipment that allows automating the grain cleaning process with minimal financial costs, and a control system that monitors the content of weed impurities in the cleaned grain, commercial grain in the exits of light impurities from the first and second aspiration channels, the exit of small impurities (the passage of the lower sieve) and the exit of large impurities (the descent from the upper sieve). The proposed set includes a level sensor, cameras, a processor with a control unit, and actuators in the form of servos. The algorithm of operation of the process control system of the grain cleaning machine is described. Continuous monitoring and adjustment of the parameters of the process flow by the control system allows one to meet all the requirements.

\section{ОЦЕНКА ВЕЛИЧИНЫ СВЧ-МОЩНОСТИ ГРУППИРОВАТЕЛЯ В ПОВТОРНОМ МАГНИТНОМ ПОЛЕ}

\author{
КУЗЬМИН Константин Анатольевич, Московский государственный университет технологий \\ и управления имени К.Г. Разумовского (Первый казачий университет) \\ моРОзов Сергей Михайлович, Московский государственный университет технологий \\ и управления имени К.Г. Разумовского (Первый казачий университет)
}

ПАВЛОВ ИГОРЬ ВАЛЕНТИНОВИЧ, Московский государственный университет технологий и управления имени К.Г. Разумовского (Первый казачий университет)

РЕУТ ВЛАДИМИР АНТОНОВИЧ, Московский государственный университет технологий и управления имени К.Г. Разумовского (Первый казачий университет)

БАЛМАШНОВА ЕЛЕНА ВИТАЛЬЕВНА, Национальный исследовательский Московский государственный строительный университет

\section{МОРОЗОВ МИХАИЛ СЕРГЕЕВИЧ, Московский авиацһинный институт}

В статъе рассматривается клистронный метод группировки в повторном магнитном поле. В длинноволновом диапазоне, кроме гирокона и магникона, исполъзуются СВЧ-тетроды и многорезонаторные клистроны. Обычные клистроны в дециметровом диапазоне имеют значительные размеры, и их применение становится проблематичным, а СВЧ-тетроды имеют значительный уровенъ мощности, но невысокий кПд и коэффициент усиления.

Введение Первый этап развития релятивистской электроники приходится на 1950-60-е гг., когда теоретически и экспериментально изучались различные способы генерации колебаний в неосвоенных тогда миллиметровом и субмиллиметровом диапазонах длин волн с помощью ускорителей-группирователей, создающих сгустки электронов, и излучателей различного типа. В качестве ускорителей-группирователей применялись линейные ускорители, ребатроны и микротроны. Излучение сгустков наблюдалось в магнитном ондуляторе и гармонотроне, в черенковском излучателе и генераторе переходного излучения, в открытых резонаторах и специальных волноводах. Были получены когерентные колебания миллиметрового и субмиллиметрового диапазонов с мощностью излучения до нескольких ватт $[4,7]$.

Исследования индуцированного излучения свободных электронов послужили основой приборов на классическом индуцированном (излучении свободных электронов) - электронных 